\title{
Reduction on Insurance Coverage for COVID-19 Benefits Everyone
}

\author{
Xiaolin Qi
}

University of North Carolina at Chapel Hill, Xi'an, 710000 China

E-mail:xiaolin@ad.unc.edu

\begin{abstract}
COVID 19 has become a generation disaster in every field of our lives. Travel ban stopped the trade; global lockdowns breed the conflicts; hospitalization stresses out the public health system. As the current solution to contain the virus starts to lose its effectiveness, this essay explores the possibility that lowering medical insurance coverage on COVID 19 will not only contain the virus but also benefits our society and improve the economy both now and in the future. By using a qualitative survey, live data provided by authorities, this essay gives the firm answer that reduces insurance coverage is an effective way that benefits everyone.
\end{abstract}

Keywords: COVID 19, medical insurance coverage, public health, socioeconomic

\section{INTRODUCTION}

By the time this essay was written, COVID 19 has infected 2.77 million people and killed 53,889 of them) [1], according to U.N, COVID 19 will cost 8.7 trillion lost for global economic output in the next two years[2]. COVID 19 has become a once-in-a-generation problem at the moment it becomes a global pandemic. Every country has different solutions to confront the pandemic. The most common onesare social distancing, travel band, monthly subsidies. Unfortunately, those actions did not seem to work in most of the countries such as the U.S and some developing countries, since social distancing will not stop people from trying to find jobs to provide their families. After all, the global unemployment rate has reached the highest in modern history. People going out to seek for a job or working under a high-risk environment have become a strong barrier on the road od containing COVID-19. After surveying around 189 people about their opinions on what drives them seeking for work or ,take high-risk jobs, medical insurance coverage stands out in the results. According to OECD statistics, in most developing countries, over 90 percent of the population is covered by either public health insurance or private health insurance. Even in developing countries, around 50 percent of the population has medical insurance.[3] The coverage rate for COVID 19 is between 80 to 95 percent varying from countries. In this paper, hypothesis that lower medical insurance benefits individuals, society, and the economy, will be proved. At the time, other solutions to contain the virus and preserve the economy tend to have less effect, and channels like lowing medical insurance coverage on COVID 19 could be a new direction to confront COVID 19.

\subsection{Individuals}

In the survey about 189 people, 76 of them are currently working in a high-risk environment; among the 15 people who are currently unemployed, 12 of which are currently seeking jobs outside their house. The survey results show that 91 percent of people working in high-risk jobs accept the job due to the possession of medical insurance, and all 12 job seekers admit they go out to seek for the job because of the public medical insurance they possess. "I have nothing to lose," said one of the job seekers. When asked about if they must pay half of their COVID treatment fee, 76 percent of all participants said they would rather stay at home depend on government subsidies. According to the survey results, medical insurance motivates some people putting themselves at risk. What people do not know is the sequela of COVID 19 after they surviving could lead to a long-term body disfunction, loss of working capability, and medical bills on chronic diseases. A study by Public Health Ontario shows that there are 78 percent chances that a patient cued from COVID 19 will suffer from long term chronic diseases. 23 percent of patients who have been to ICU would suffer from lifelong heart issues and lung issues that may become lethal one day[3]. If that can reduce the medical insurance coverage, more people can be saved from sufferingthe lifelong chronic diseases brought by COVID 19. How much should we lower the insurance coverage? Most people decide to work in high-risk environments or go out to seek jobs by the value they receive from risking their lives. According to American health insurance, the current health insurance plan covers around 80 to 90 percent of the treatment fee, and government subsidy covers the uninsured or public health plan participant almost 100 percent of the treatment in some country. According to e-health, an average of $\$ 4500$ was spent by patients who have COVID 19. When making decisions, a job that pays more than $\$ 6000$ would be considered as a valid option by 
the job seekers to consider the value loss by having COVID 19, which is the treatment fee after medical insurance and value loss from not working for the treatment period. For some people, the salary of the job could be lower since they are covered by government insurance. The existence of jobs like that will attract unemployed workers to join the army of seeking jobs regardless of the risk. Still, the demand for workforce outrun the supply. If people have to pay more when they get COVID 19, the value of accepting high-risk jobs with low payment and seeking jobs will drop, thus letting more people stay at home living on government subsidies. Also, a study from CDC shows 64 percent of American workers who refuse to wear Mask in high-risk working environments. By lowering the medical insurance coverage, it would be able to force people to wear Mask since their payment may not be able to cover their fees if they got COVID. So many lives would be saved by simply lower insurance coverage. And it is not only benefits individuals but also society.

\subsection{Society}

Our society is threatened by the conflicts caused by COVID 19. The longer it took for us to control the virus, the higher risk we will put on our society. By reducing the medical insurance coverage on COVID 19, we will be able to shorten the time of lockdowns and restore the order of our society as soon as possible. COVID 19 could be called the largest public health failure in modern history. No one was ready for this, thus causing a huge shortage of medical supplies and medical workers. Many health workers have to work a double shift to keep the hospital running, and due to the travel ban, the FDA reported a lack of supply on 21 drugs that related to COVID 19. The development of vaccines also required sufficient medical supply, which is becoming unknown due to the rising speed of COVID 19. If we can make sure more people stay at home instead of outside working or finding jobs, we would release the high pressure put on our public health system, thus put more effort into developing vaccines. Social unrest has become the biggest threat to our society during the COVID 19 period. Strict lockdowns and travel ban have put our society under dissatisfaction, riots, violence, and other kinds of conflicts. According to Dr. Roxana Gutiérrez-Romero from the Queen Mary University of London, although the recently implemented social distancing measures and lockdowns might curb the spread of the coronavirus, an issue of major concern is the potential risks of social unrest given the sudden loss of jobs and livelihoods. The longer the lockdowns the longer our society facing the threat of meltdown. COVID 19 also bring more uncertain factor to the mental health of the society such as fear, inequality, and conflicts between wealth and poor. Those factors will pose a long term consequence in our society. According to the COVID-19 Risks Outlook report published by the World Economic Forum recently, up to 37 percent adults showed signs of psychological distress and depression, up to 45 present felt adverse effects on mental health, up to 70 percent felt the period was most stressful in their carrier. More than 80 percent of students are feeling stressed due to the increased likelihood of dropout. [4]Those numbers are still rising. If we do not do anything to stop the virus from spreading, our society will be facing long term conflicts that may resolve wars. Although lowing the medical insurance coverage will pose a higher threat to conflict between rich and poor, longer-term lockdowns will make things worse than lowing the medical insurance coverage. Lowing medical insurance coverage should be able to keep most of the job seekers at home or at least increase people's consciousness of wearing protections. Once everyone chose to either stay at home or wearing protection, we should be able to control the virus within three months like China did. The removal of lockdowns, travel restriction, and social distancing will gradually release the mental stress and economic stress of people, and all the conflict facing by our society will finally start to resolve before causing long term damage. When other solution to release tension on our society did not work well, why not try some new ideas that may even help to solve economic issues in the future.

\subsection{Economics}

COVID 19 has put the global economy into the worst recession in modern history. In the future, the sequela of COVID 19 would lead to further damage to the global economy. Redirect funding on medical insurance to other fields such us subsidies check to households which keep people stay at home and subsidies to banks, which release the pressure of paying debts. Reduce insurance coverage on COVID 19 will eventually release on the global economy both now and in the future. According to the World Bank, the global economy will shrink 5.2 percent in 2020, and the U.S bureau state U.S has reached the worst unemployment figure in the last 72 years.[5] Under the current recession, the U.S government paid roughly 600 million dollars to the uninsured people for treatment of COVID 19, and more to help those who can not afford treatment for COVID 19 [6]. Imagine 20 million uninsured people who get the cue from coronavirus will be facing a long term treatment of chronic disease caused by coronavirus. That would be a huge number for a country like the U.S, not even mention those third world countries. If the government lower insurance coverage on COVID 19, the money used to pay medical insurance will be saved and there will undoubtedly be fewer people who will get COVID 19. Therefore, the money saved from medical insurance can be used to boost the economy, and with few people getting COVID 19 less future spending will also be saved which will help increase the speed of recovery. Economy recovery will be a long rough journey for us, so the workforce who are unemployed now will become the future of recovery. Although lowering the insurance coverage will increase the risk of bankruptcy, it will raise the wage of high-risk jobs thus increase consumer spending and preserve valuable workforce for future recovery. When most of the government are struggling 
with the poor financial situation, why not try to cut some spending and print less money so that the global economy will not fall into massive inflation after the pandemic.

\subsection{Reflection}

What we cannot avoid is the potential risk of lowering medical insurance coverage may have collateral damage to those who are already suffering from COVID 19 and people who cannot afford the treatment fee. There will be a higher rate of bankruptcy once the medical insurance coverage gets decreased. To help reduce the collateral damage, the government can set some special subsidies to help those who are bankrupted. Still, if the COVID 19 gets contained by ingreducing the insurance coverage, the benefits will outrun the damage. Anyway, when other methods of containing viruses start to work less efficiently, we believe cutting insurance coverage could be a solution that is both risky and effective. Although we mainly talk about how the reduction in insurance coverage for COVID 19 will contain the virus, release stress on society, and improve the financial situation of governments, my research still has some inaccuracy on the research. The survey used the method of qualitative research instead of quantitative which make the survey may not be able to accurately apply to the general population. Because many third world countries do not have accurate data released, many results may not apply to some developing countries. COVID 19 is a relatively new event for everyone so the information we got is restricted by the lack of research. Thus the results of this essay still need more detailed analysis on the decision-making process that makes people go out seeking jobs or work under high risk. Most importantly, the relationship between value loss by COVID 19 and value gain by working or seeking employment at high risk environment need more detailed calculation to get the best result of how much coverage on COVID 19 should be reduced to achieve the most effective on benefits everyone.

\section{CONCLUSION}

COVID 19 has already brought huge damage to our society and it is still harming our people, society, and economy. There is a long road for a cue to come out and stop the pandemic. Before that, COVID19 will continue to bring chronical disease to people around the word, disrupt the society, and bring global economy to a recession that my take decades to recovery. If reducing COVID19 medical coverage will bring the damage cause by the pandemic to a minimal value, this method should be considered. After all, as this paper prove and try to suggest. Lower medical insurance coverage will prevent lifelong COVID 19 chronic disease by make people stay at home; ease the social unsteady cause by the COVID 19 by contain the virus sooner; rescue global economy from recession by reduce government deficit. When other method that try to contain COVID 19 stop working effectively, new method should be given opportunity.

\section{ACKNOWLEDGMENT}

I would like to give thanks to the professors, peers, and friends who give me the idea of this paper and support me on my way to prove my hypophysis. Also, I would like to show my deepest gratitude to those who participate the survey and made my idea a persuasive hypophysis. Without all their participation and instruction, I could not turn my idea in to this persuasive paper.

\section{REFERENCES}

[1] Reinhart, C. (2020) The pandemic depression. Foreign affairs. Volume 99, number 5

[2] Brien, S. (2020) Here's what you need to know when it comes to paying for coronavirus treatment. https://www.cnbc.com/2020/04/09/heres-what-you-nee d-to-know-about-coronavirus-treatment-costs.html

[3] Public Health Ontario. (2020) Long-Term Sequelae and COVID-19 - What We Know So Far. https://www.publichealthontario.ca/-/media/documents/ ncov/covid-wwksf/2020/07/what-we-know-covid-19-lo ng-term-sequelae.pdf?la=en

[4] Stephen, M. (2020) Schieffer Series: COVID-19 and Societal Instability: Where Are We Heading? https://www.csis.org/events/online-event-schieffer-serie s-covid-19-and-societal-instability-where-are-we-headin $\mathrm{g}$

[5] U.N Statistics. (2020) Real-time data show virus hit to global economic activity".

https://www.un.org/en/coronavirus

[6] Levitt, L \& Schwartz, K. (2020) Estimated Cost of Treating the Uninsured Hospitalized with COVID-19. https://www.foreignaffairs.com/articles/united-states/20 20-08-06/coronavirus-depression-global-economy 